\title{
CONTEXTUAL REDEFINITION STRATEGY FOR MANAGEMENT STUDENTS
}

\author{
Berlin Insan Pratiwi \& Dwi Lia Rakhmasari \\ STIE Putra Bangsa Kebumen \\ bipratiwi@gmail.com
}

\begin{abstract}
As Contextual Redefinition (CR) provides chances to guess meaning of word by its surrounding, it is expected to encourage students to participate more by contributing in the required steps. This study aims to measure implementation effects (score and class involvement) of $C R$ toward Management study programme students and to find out their attitude of it. Conducted as an experimental research, this research involves three cycles of treatment. It is fulfilled with description of students attitude toward CR implementation in which the data is gained through questionnaire. Three findings are as follow: 1) CR provides mean score betterment of 61.58 on pretest to 69.11 on post-test with the absence of saturation until the end of cycle three; 2) CR activates students with class involvement increase of 16.19 on each cycle; and 3) CR is favoured by $47.54 \%$ students and $55.88 \%$ students expecting $C R$ to be applied in every reading section. The findings indicate that despite having good significance in improving the score, this strategy is favored by less than half of students and only half and so will require its application in the process of class lecturing.
\end{abstract}

Keywords: contextual redefinition, economic English for EFL

\section{Introduction}

In general, English in Indonesia is regarded as part of foreign language in which its position is the same as Mandarin, German, French, and others which then causes Indonesia to be part of the expanding circle in terms of English usage. The inclusion of English as foreign languag since early education does not always have an impact in line with the learning achievement of learners. The number of learners who are taught English since junior high school but do not master English until higher education can be assumed to be quite a lot. Although the effort to include English in the education curriculum is not a new thing, but data associated with the results of teaching has not been proven any betterment. The status quo brings impact for English which is still recognized as a foreign language and difficult for Indonesian learners.

The Management study program of STIE Putra Bangsa includes Bahasa Inggris I in the first semester and Bahasa Inggris II in the second semester. Through these two subjects, students are expected to gain understanding of English for economic and business purposes and be able to apply their understanding in productive oral and written outcome.

Based on the results of the previous year's UTS and UAS evaluation, it is stated that the delivered economic and business English language material are not well absorbed by students, especially in the significance of understanding and adding vocabulary related to economics and business fields. Thus it is necessary to make efforts to improve students' vocabulary understanding and addition.

Various efforts are made to improve understanding and the addition of economic and business vocabulary. Improvement in material delivery is one of the efforts which tailored to the outcomes of the learning process. In relation to one of the outcomes of both Bahasa Inggris I and Bahasa Inggris II in STIE Putra Bangsa namely understanding and using the English term in economic and business context, the CR learning strategy is chosen. This selection is based on the purpose of the $\mathrm{CR}$ which is to help the learner in identifying unfamiliar words/terms based on their linkages in context.

$\mathrm{CR}$ is a learning strategy focusing on increasing vocabulary mastery. Gambrell and Hadley (2006) in Asri (2013) state that the use of this strategy allows learners to be in a learning atmosphere that has the potential to produce significant vocabulary mastery developments. The use of this strategy means conditioning the learner to predict the meaning of a word. The word may have a meaning that is 
already known by the learner, but it becomes incompatible with the context if it is interpreted in that certain meaning. In the learning process the meaning of a word is estimated with the help of clue available in sentence or paragraph.

There are several studies that have been carried out regarding the application of CR. Jenkin, Matlock, and Slocum (1989) and Souresjani (2011) state that the use of CR has effectiveness in improving learner ability in vocabulary mastery. Here are some of the advantages of $\mathrm{CR}$ implementation:

1. Bean, Baldwin, and Readence (2012) state that learners are actively involved in finding the meaning of words when CR is used.

2. Martin (1985) in Chou (2011) states that learners tend to have more interest in finding meaning when $\mathrm{CR}$ is used.

3. Sharzad and Derakhshan (2012) state that the words obtained through more help (clues) have the ease of learning and tend to be remembering longer. This is in line with the impression students get toward an active involvement obtained when finding out the meaning of words.

The discovery of meaning in $\mathrm{CR}$ can also be determined by understanding word order, syntax, main ideas, and examples contained in the text. This is related to the statement of Soureshjani (2011) that the results of using CR are also influenced by learner's understanding toward grammar. He adds that this grammar understanding is used to guess the meaning of words/terms with what is obtained in the grammar contained in the text. $\mathrm{CR}$ encourages learners to:

1. Focus on things that are clearly understood in the text which then can be used as clues.

2. Declare in detail the things that are the main topic of the text.

3. Use the results of observations regarding these details as an aid to understand unfamiliar words/terms through a context that has been understood.

Above all those advantages, CR is seen as having shortcomings. The main thing considered as the lack of CR is that the learner is likely to experience fatigue when trying to identify unfamiliar words. This fatigue occurs when the learner only focuses on the word as an element separate from the context. In addition, learners have the potential to make incorrect guesses. This alleged inaccuracy is probably minimized by adjusting the level of words, sentences, and texts based on the learner's ability (Hunt and Beglar, 2005).

\section{Method}

This experimental research comes with four stages including pretest test, cycles, posttest, and questionnaire. The use of the mixed methods is employed by the researcher. This method is employed in which quantitative method is used to measure the effectiveness of CR learning strategy usage through statistical test analysis of quantitative data in the form of test results, while qualitative method is used to determine students' attitudes toward the use of CR with qualitative data in the form of questionnaire.

There are two classes as control group and two classes as treatment group. Total subject of this research is 168 students spread equally in both control and treatment group.

Data are collected by using two instruments, namely vocabulary tests (pretest and post- test) and questionnaire. Vocabulary tests are tests aimed at revealing students' vocabulary understanding and addition before and after treatment. Questionnaire is used to determine students' attitudes toward the application of CR.

The null hypothesis in this study is:

$\mathrm{H}_{0}$ : There is no effect of CR usage in improv-

ing students' vocabulary understanding and addition (in the form of scores) in economic and business fields.

Quantitative data processing of CR implementation is done by t-test and test of hypothesis. T-test is used to compare the mean of two groups that are not related to each other. The t-test in this study is conducted in the technique of the independent-sample t-test statistical technique with the help of IBM SPSS Statistics 23 analysis tool. Test of hypothesis is used to answer question that assumes the null hypothesis. The purpose of this test is to find out whether there is a difference between the average learning outcome (score) before the treatment incompared to the average learning outcome (score) after the treatment $(\mu 1<\mu 2)$.

Qualitative data analysis is carried out by researcher as human instrument to find the tends of students' attitudes towards CR usage. Researcher uses the Liker scale to classify students' attitudes toward the use of CR.

\section{Findings and Discussions}

The result of the research shows that $C R$ strategy significantly increases the scores ob- 
tained. Students are able to motivate themselves to reveal the meaning of unfamiliar words by applying CR steps in a structured sequences and with or without continuous supervision from the lecturer. These findings are in line with the findings of Rijal (2016) which states that CR is appropriate for Pharmacy students and students with other ESP needs. This study also finds that although having good significance in increasing scores, this strategy is not well favoured by the research subjects and only half of the total research subjects require its application in lecturing process.

\section{T-Test}

This test is used to compare the average of two groups that are not related to each other. By doing this it will be revealed whether the two groups have the same average or not significantly. The test in this study uses the independent-sample t-test technique with the help of IBM SPSS Statistics 23. The stages of this test are: 1) testing the variance assumptions of the two samples by looking at the Levene test and 2) looking at the value of t-test to determine whether there is a significant difference in average scores with the following decision-making conditions:

If probability $>0.05, \mathrm{H}_{0}$ is accepted.

If probability $<0.05, \mathrm{H}_{0}$ is rejected.

$\mathrm{H}_{0}=$ there is no difference between the mean control group score and the treatment group score.

The computation is presented in five sections including t-test result for pretest, $t$ test result for first cycle, $t$-test result for second cycle, t-test result for third cycle, and t-test result for post-test. The followings are the result of computation:

\section{Pretest}

Levene's test for equality of variances has significance value of $0.354(p>0.05)$. It shows that the two variances are the same, so the use of variance to compare the population average ( $t$-test or equality of means) in the $\mathrm{t}$ test is based on equal variance assumed. At equal variance assumed it is obtained $t$-value of -0.497 with a significance level of $p=0.620$. These results indicate that $p>0.05$. The mean value in the control group is 60.4412 and in the treatment group is 61.5441. It indicates that the differences in learning outcomes between control group and treatment group is very small with only 1.1029 . These findings indicate there is no difference in learning outcomes between the control group and the treatment group in pretest score.

\section{First Cycle}

Levene's test for equality of variances has significance value of 0.885 ( $p>0.05)$. It shows that the two variances are the same, so the use of variance to compare the population average ( $t$-test or equality of means) in the $t$ test is based on equal variance assumed. At equal variance assumed it is obtained $t$-value of 0.674 with a significance level of $p=0.501$. This result indicates that $p>0.05$. The mean value in the control group is 54.7059 and in the treatment group is 53.1618. It indicates that the differences in learning outcomes between control group and treatment group is very small with only 1.5441 . These findings indicate there is no difference in learning outcomes between the control group and the treatment group in the first cycle.

\section{Second Cycle}

Levene's test for equality of variances has significance value of $0.800(p>0.05)$. It shows that the two variances are the same, so the use of variance to compare the population average (t-test or equality of means) in the t-test is based on equal variance assumed. At equal variance assumed it is obtained $t$-value of 4.332 with a significance level of $p=0.000$. This result indicates that $p<0.05$. The mean value in the control group is 52.1324 and in the treatment group is 61.6176. Based on the statistical finding, it is said that after getting second cycle the learning outcomes of the treatment group is higher than the control group.

\section{Third Cycle}

Levene's test for equality of variances has significance value of $0.111(p>0.05)$. It shows that the two variances are the same, so the use of variance to compare the population average (t-test or equality of means) in the $t$ test is based on equal variance assumed. At equal variance assumed it is obtained $t$-value of -6.044 with a significance level of $p=0.000$. This result indicates that $p<0.05$. The mean value in the control group is 52.7206 and in the treatment group is 65.2941. Based on the statistical finding, it is said that after getting the third cycle the learning outcomes of the 
treatment group is higher than the control group.

\section{Post-test}

Levene's test for equality of variances has significance value of $0.187(\mathrm{p}>0.05)$. It shows that the two variances are the same, so the use of variance to compare the population average ( $t$-test or equality of means) in the $t$ test is based on equal variance assumed. At equal variance assumed it is obtained $t$-value of -5.357 with a significance level of $p=0.000$. This result indicates that $\mathrm{p}<0.05$. The mean value in the control group is 56.9118 and in the treatment group is 69.1176. Based on the statistical finding, it is said that the learning outcomes of post test of the treatment group is higher than the control group.

\section{Test of Hypotesis}

This test is used to answer questions that assume the null hypothesis. The purpose of this test is to find out whether there is a difference between the average learning outcomes before the cycle with the average learning outcomes after the cycle $(\mu 1<\mu 2)$. The hypotheses in this test are:

$$
\begin{aligned}
& \mathrm{H}_{0}: \mu_{1}=\mu_{2} \\
& \mathrm{H}_{1}: \mu_{1}<\mu_{2}
\end{aligned}
$$

Decision making in this test is based on the following conditions:

If $\mathrm{Z}_{0} \leq \mathrm{Z}_{a}, \mathrm{H}_{0}$ is accepted.

If $\mathrm{Z}_{0}>\mathrm{Z}_{\mathrm{a}}, \mathrm{H}_{0}$ is rejected.

The significant level $(\alpha)$ in this study is 0.05 . Thus $Z_{\alpha}$ is equal to 1.65; so that the critical area is described as follow:

\section{Pretest - First Cycle}

The hypotheses in this test are:

$\mathrm{H}_{0}$ : the average score of first cycle equals to the pretest

$\mathrm{H}_{1}$ : the average score of first cycle is higher than the pretest

$$
\begin{array}{rlrlrl}
\bar{X}_{1}=53,16 & \bar{X}_{\text {pre }}=61,54 & \mathrm{~S} \bar{x} 1-\bar{x} \text { pre } & =\sqrt{\frac{S 1^{2}}{n}}+\sqrt{\frac{S p r e^{2}}{n}} & \mathrm{Z}_{0} & =\frac{\bar{x} 1-\bar{x} p r e}{\text { S } \bar{x} 1-\bar{x} p r e} \\
S^{2}=\frac{\sum(X-\bar{X})^{2}}{n-1} & S^{2} & =\frac{\sum(X-\bar{X})^{2}}{n-1} & & \sqrt{\frac{179,03+139,74}{68}} & =\frac{53,16-61,54}{2,17} \\
=\frac{11995,22}{67} & & =\frac{9362,87}{67} & & =\sqrt{\frac{318,77}{68}} & =\frac{-8,38}{2,17} \\
=179,03 & & =139,74 & & =\sqrt{4,69} & =-3,86
\end{array}
$$

Conclusion:

$\mathrm{Z}_{0}<\mathrm{Za}(-3.86<1.65)$, then $\mathrm{H}_{0}$ is accepted.

Thus it is stated that the average score of first cycle is equal to pretest.

\section{First Cycle - Second Cycle}

The hypotheses in this test are:

$\mathrm{H}_{0}$ : the average score of second cycle equals to the first cycle

$\mathrm{H}_{1}$ : the average score of second cycle is higher than the first cycle

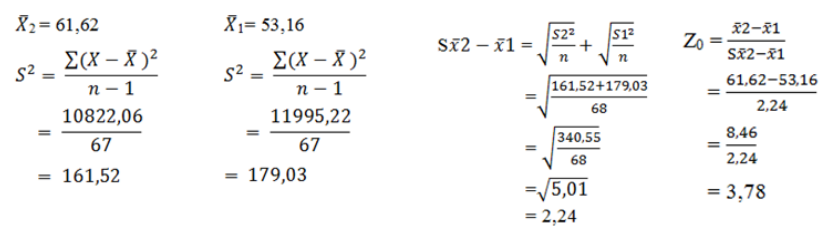

Conclusion:

$\mathrm{Z}_{0}>\mathrm{Za}(3.78>1.65)$, then $\mathrm{H}_{0}$ is rejected. Thus it is stated that the average score of second cycle is higher than the first cycle.

\section{Second Cycle - Third Cycle}

The hypotheses in this test are:

$\mathrm{H}_{0}$ : the average score of third cycle equals to the second cycle

$\mathrm{H}_{1}$ : the average score of third cycle is higher than the second cycle

$$
\begin{array}{rlrlrl}
\bar{X}_{3}=65,29 & \bar{X}_{2}=61,62 & \mathrm{~S} \bar{x} 3-\bar{x} 2 & =\sqrt{\frac{S 3^{2}}{n}+\sqrt{\frac{S 2^{2}}{n}}} & \mathrm{Z}_{0} & =\frac{\bar{x} 3-\bar{x} 2}{\mathrm{~S} \bar{x} 3-\bar{x} 2} \\
S^{2}=\frac{\sum(X-\bar{X})^{2}}{n-1} & S^{2}=\frac{\sum(X-\bar{X})^{2}}{n-1} & & \sqrt{\frac{126,77+161,52}{68}} & =\frac{65,29-61,62}{2,06} \\
=\frac{8494,12}{67} & =\frac{10822,06}{67} & & =\sqrt{\frac{288,29}{68}} & =\frac{3,67}{2,06} \\
=126,77 & & =161,52 & & =\sqrt{4,24} \\
& & & =2,06 & =1,78
\end{array}
$$

Conclusion:

$\mathrm{Z}_{0}>\mathrm{Za}(1.78>1.65)$, then $\mathrm{H}_{0}$ is rejected. Thus it is stated that the average score of third cycle is higher than the second cycle.

\section{Third Cycle - Post-test}

The hypotheses in this test are:

$\mathrm{H}_{0}$ : the average score of third cycle equals to the post-test

$\mathrm{H}_{1}$ : the average score of third cycle is higher than the post-test

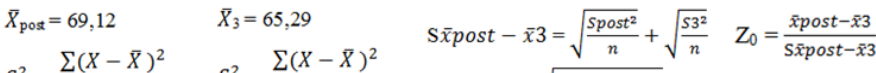

$$
\begin{aligned}
& S^{2}=\frac{\sum(X-\bar{X})^{2}}{n-1} \quad S^{2}=\frac{\sum(X-\bar{X})^{2}}{n-1} \quad=\sqrt{\frac{146,22+126,77}{68}} \quad=\frac{69,12-65,29}{2} \\
& =\frac{9797,06}{67}=\frac{8494,12}{67}=\sqrt{\sqrt{272,99}} \quad=\frac{3,83}{2} \\
& =146,22=126,77 \\
& \begin{array}{l}
=\sqrt{4,02} \\
=2
\end{array} \\
& =1,915
\end{aligned}
$$

Conclusion:

$\mathrm{Z}_{0}>\mathrm{Za}(1.915>1.65)$, then $\mathrm{H}_{0}$ is rejected. Thus it is stated that the average score of post-test is higher than the third cycle.

Subjects' Participation in CR Application The following tables show the effect of $C R$ in 
gaining students to participate actively in class activity. The following tables provide descriptions on the number of students get involve in CR application.
Cycle 1 is a trial period for research subjects to apply CR. Overall observation in this cycle shows that classes conditions are still the same as pre-cycle conditions. Subjects

Table 1. Students Participation in Cycle 1

\begin{tabular}{|l|c|c|c|c|c|}
\hline Participation & \multicolumn{2}{|c|}{ Class 1 } & \multicolumn{2}{c|}{ Class 2 } & Average \\
\hline Very Active & 4 & $12,12 \%$ & 4 & $11,43 \%$ & $11,77 \%$ \\
\hline Active & 8 & $24,24 \%$ & 9 & $25,71 \%$ & $24,97 \%$ \\
\hline Not Active & 21 & $63,64 \%$ & 22 & $62,86 \%$ & $63,25 \%$ \\
\hline Total & 33 & $100 \%$ & 35 & $100 \%$ & $100 \%$ \\
\hline
\end{tabular}

who are actively involved in this first cycle are subjects who are also actively participate in daily activities. At the beginning of the first cycle, most of the subjects seem to still be confused about the sequences to be done. The subjects ask many questions freely to their surrounding friends to follow the instructions given.
Participation in following the steps of CR in the second cycle has improved. This is measured by the level of involvement and participation of research subjects during the cycle. Subjects begin to master the sequences to be carried out based on the CR strategy and begin to be able to implement these sequences more independently.

Table 2. Students Participation in Cycle 2

\begin{tabular}{|l|c|c|c|c|c|}
\hline Participation & \multicolumn{2}{|c|}{ Class 1 } & \multicolumn{2}{c|}{ Class 2 } & $\begin{array}{c}\text { Participation } \\
\text { Average }\end{array}$ \\
\hline Very Active & 9 & $27,27 \%$ & 13 & $37,14 \%$ & $32,20 \%$ \\
\hline Active & 9 & $27,27 \%$ & 8 & $22,86 \%$ & $25,06 \%$ \\
\hline Not Active & 21 & $45,45 \%$ & 14 & $40,00 \%$ & $42,72 \%$ \\
\hline Total & 33 & $100 \%$ & 35 & $100 \%$ & $100 \%$ \\
\hline
\end{tabular}

In the discussion sessions conducted in groups, there are more students who states their opinions and actively give their opinions. Besides, the activity of using a dictionary looks more conditioned with the calm atmosphere during the search for meaning. Students begin to seem to try to adjust the suitability of the meaning of the words found in the dictionary according to the context required in the task.

In general, in this third cycle it is said that students have mastered the sequences of CR. Compared to the average number of students who do not participate in implementing
CR sequence, it is stated that the decrease occurs significantly. In the first cycle there are $63.25 \%$ of the total subjects identified as passive subjects, in the second cycle the number decreases to $42.72 \%$, and in the third cycle the number decreases to $30.82 \%$. From these statistics it is firmly confirmed that CR strategy significantly increases the participation of the research subjects. Thus subject participation and CR mastery influence the ability of research subjects to become independent learners so that they can apply these strategies to a wider scope.

Table 3. Students Participation in Cycle 3

\begin{tabular}{|l|c|c|c|c|c|}
\hline Participation & \multicolumn{2}{|c|}{ Class 1 } & \multicolumn{2}{c|}{ Class 2 } & $\begin{array}{c}\text { Participa-tion } \\
\text { Average }\end{array}$ \\
\hline Very Active & 17 & $51,52 \%$ & 20 & $57,14 \%$ & $54,33 \%$ \\
\hline Active & 6 & $18,18 \%$ & 4 & $11,43 \%$ & $14,08 \%$ \\
\hline Not Active & 10 & $30,30 \%$ & 11 & $31,34 \%$ & $30,82 \%$ \\
\hline Total & 33 & $100 \%$ & 35 & $100 \%$ & $100 \%$ \\
\hline
\end{tabular}




\section{Subjects' Attitude toward CR Application}

Based on research findings it is revealed that $47.54 \%$ of the research subjects favour the application of CR in English class and 55.88\% of the research subjects require the implementation of this strategy in very reading session. Thus it is stated that there is no high percentage regarding to the level of preference for $C R$ application submitted by research subjects in the questionnaire. In addition, the percentage of research subject number agreeing the use of $\mathrm{CR}$ in every reading session with those who do not agree is also said to be almost equal.

1. Other findings obtained in the research regarding the attitude of the research subject to the application of this strategy are the recognition of the three difficulties faced by students. These difficulties include:

2. Difficulty in guessing the meaning of words/phrases contained in sentences that are considered as difficult sentences. Not all sentences can be classified in the type of sentence that is relatively easy to understand by the research subject. Words/ phrases contained in relatively difficult sentences are challenges for students. The existence of this kind of difficulty must be addressed by the lecturer by better adjustment of the sentence difficulty level used so that it is more compatible with the students. This finding is in line with Asri's finding (2013) which explains that in her interview students have difficulty in guessing meaning because the sentence presented is considered as too difficult. This is also attributed to Nation (2001) which states that in teaching using $C R$ the teacher must pay attention to word and text selection.

3. Difficulty in guessing the meaning of words/phrases due to lack of grammatical understanding. Many of English grammar is not mastered by the research subjects so that this is considered to be one of the causes of the difficulty in applying CR. Soureshjani's statement (2011) supports this finding. He states that the use of CR also requires the learner to have sufficient grammatical knowledge so that he can use the contextual grammar clue contained in the text.

4. Difficulty in doing steps in sequence. Not all research subjects are able to apply this strategy in accordance with the sequence. In the questionnaire, the research subjects reveal that this kind of layered strategy is considered to be quite inconvenient and required patience to be carried out. Research subjects consider that this strategy as an unpractical strategy and cannot be applied immediately.

\section{Conclusion}

CR is a proper learning strategy applied to students of the Management study program because it significantly increases the scores. Compared score of pretest mean and post-test are 61.58 and 69.11 with score increases in cycles 2 and 3 . There is no score increase saturation until the end of cycle 3 . Thus $\mathrm{H}_{0}$ of this study is rejected.

CR helps students to become active and independent learners in English lesson, especially in the activity of understanding the meaning of words in economic and business discourses. It is proven by the level of activity in the classroom which increases significantly. In cycle 1 there are $63.25 \%$ of students having less participation, in cycle 2 there are $42.72 \%$ of students having less participation, and in cycle 3 there are $30.86 \%$ of students having less participation. Thus it is concluded that the students' participation increases significantly.

The application of $\mathrm{CR}$ is favored by $47.54 \%$ of research subjects and is expected to be always applied in every reading session by $55.88 \%$ of the research subjects. It indicates that even though it has good significance in increasing scores, this strategy is not very well favoured by the research subjects and only half of the total subjects require CR application in lecturing process.

\section{References}

Asri, Nika. (2013). The analysis of two prereading strategies: contextual redefinition and word list in EFL learners' reading comprehension. Journal of English Education, Vol. 1, No.2, pp. 47-56.

Bean, T., et all. (2012). Content-area literacy: reaching and teaching. Huntington Beach: Shell Education.

Chou, P. T. (2011). The effects of vocabulary knowledge and background knowledge on reading comprehension of Taiwanese efl students. Electronic Journal of Foreign Language Teaching, Vol. 8, No. 1, 108 -115 .

Hunt, A., \& Beglar, D. (2005). Current research and practice in teaching vocabulary. Cam- 
bridge: Cambridge University Press.

Jenkins, J. R., Matlock, B., \& Slocum, T. A. (1989). Two approaches to vocabulary instruction: the teaching of individual word meanings and practice in deriving word meaning from context. Reading Research Quarterly, Vol. 24, No. 2, 215235.

Kachru, B.B., Kachru, Y. \& Nelson, C.L. (2011). The handbook of world Englishes. Oxford: Blackwell Publishing Ltd.

Nation, I.S.P. (2001). Learning vocabulary in another language. Cambridge: Cambridge University Press.

Rijal, A.S. (2016). English learning startegy by applying CR strategy for ESP class. Proceedings of the Fourth International Seminar on English Language and Teaching, ISLT-4.

Shahrzad, A. \& Derakhshan. (2011). A. The effect of instruction in deriving word meaning on incidental vocabulary learning in EFL context. World Journal of English Language, Vol . 1, No. 1.

Soureshjani, K. H. (2011). The effect of contextualizing and decontextualizing techniques on lexical-oriented knowledge of Persian EFL language learners. Theory and Practice in Language Studies, Vol. 1, No. 5, 547-552. 